\title{
Distribution Factors of Candida species in Respiratory Tract of Elderly Population of Kathmandu.
}

\author{
${ }^{1}$ Mamita Khaling Rai, ${ }^{1}$ Krishna Gurung, ${ }^{2}$ Devraj Joshi \\ ${ }^{1}$ Department of Microbiology, Pokhara Bigyan Tatha Prabidhi Campus, Pokhara, Nepal \\ ${ }^{2}$ Central Department of Microbiology, Tribhuvan University, Kathmandu, Nepal
}

\begin{abstract}
Though normal flora of upper respiratory tract, Candida species are a significant clinical problem for a variety of immune compromised patients worldwide. Impaired salivary gland function, drugs, dentures, high carbohydrate diet, age, smoking, diabetes mellitus, Cushing's syndrome, malignancies, and immunosuppressive conditions are the associated risk factors for the Candidiasis. The study was designed with the objectives of describing the distribution pattern of Candida species and some molds in the elderly and non elderly population randomly sampled from the three Oldage Care Centers. A total of 304 samples each of sputum and throat swabs were collected from the study objects having age 20-80 years. The specimens were cultured on Sabouraud's Dextrose Agar (SDA). Candida isolates were identified on the basis of Gram stain, germ tube test, production of chlamydospore, sugar fermentation and assimilation test. The mold isolates were identified by cultural and microscopic characteristics. Out of total 304 samples of each sputum and throat swabs $16.45 \%$ and $5.3 \%$ samples respectively were growth positive for fungal culture. Among elderly population, 32.87\% (47/143) of sputum and 9.8\% (14/143) throat swabs showed culture positivity. In case of non elderly population however only 1.9\% (3/161) sputum and 1.24\% (2/161) throat swab samples were culture positive. In total, 56 Candida isolates (41 from sputum and 14 from throat swabs) were obtained. Significantly higher number of isolates was obtained from elderly population (38 from sputum and 12 from throat swabs) than non elderly population. Among three antimycotic drugs used, the Candida isolates were highly susceptible against Ketoconazole and resistant towards Fluconazole. Candida distribution was significantly associated with the age, respiratory tract problem and smoking habits of the study population. Elderly population having age above 50 years are in the high risk of drug resistant Candida infection.
\end{abstract}

Key Words: Candida, elderly population, sputum, throat swab, antimycotic susceptibility.

Corresponding address: Mamita Khaling Rai, Department of Microbiology, Pokhara Bigyan Tatha Prabidhi Campus, Pokhara, Nepal.

E-mail: mamitarai18@gmail.com

\section{INTRODUCTION}

Candida is an opportunistic fungus that normally inhabits the mouth, throat, gastrointestinal tract and vagina. ${ }^{1}$ In the last two decades a steady increase in nosocomial infections caused by Candida species has been seen due to its endogenous origin. Candida species have been the third most common pathogen isolated from patients with lower respiratory tract infection. ${ }^{2,3}$ There are several types of Candida infections, like candidiasis involving primarily the mucosal surfaces (thrush) of the throat, respiratory tract and urogenital tract, candiduria, Candida infection of gastointestinal tract, invasive candidiasis, including candidemia and disseminated candidiasis with deep organ involvement. ${ }^{4,5}$

Risk factors of candidial infection include impaired salivary gland function, drugs, dentures, high carbohydrate diet, and extremes of life, smoking, diabetes mellitus, Cushing's syndrome, malignancies, and immunosuppressive conditions. ${ }^{6}$ Candida species are prevalent in the oral cavity, among elderly population and immunosuppressed patients. ${ }^{7}$ Currently, there are more than 150 known species of Candida. However only 15 of these species are isolated from patients as infectious agents. Among these in 95\% of infections, the pathogens involved are C. albicans, C. glabrata, $C$. parapsilosis, C. tropicalis, and C. krusei. ${ }^{8,9,10,11}$

Since concurrent with the increase in fungal infections, a large variety of antifungal drugs are available with different spectrum of activity and a high variability in the susceptibility of clinical isolates to antifungal agents has been documented. ${ }^{2,12}$ Recent reports indicate nonalbicans infections are on the rise, often accounting for more than $50 \%$ of candidiasis found in the infected population. Additionally, drug resistance may vary by species. ${ }^{13}$

The present study is based upon the hypothesis that colonization of Candida and molds in respiratory tract of elderly population is higher than non elderly population. Therefore the present study has been 
designed with objective to describe distribution pattern and risk factors of different species of Candida and in upper and lower respiratory tract of selected elderly and non elderly population of Kathmandu. Furthermore the antimycotic susceptibility testing of Candida isolates have also been described. The study possibly highlights importance of screening of Candida in elderly population.

\section{MATERIALS AND METHODS}

Altogether 304 populations with age above 20 years were taken for the study. Population above 50 years was categorized as 'elderly population' and population having age equal or less than 50 years was categorized as 'non elderly population'. For elderly population three Old age Care Centers (Samaj Kalyan Centre, Pashupati, Nisaya Sewa Sadan, Baneshwor and Birddha Vewasthapan Kendra, Teku) were selected and non elderly populations were selected from different regions of Kathmandu. Similarly, a structured questionnaire on name/code, age, demographic data, health problem, respiratory tract problem, smoking and drinking habits, disease history, symptoms and other information were recorded with taking verbal consent, by interviewing with them or their care-takers.

Throat swabs and sputum of individuals were collected as samples for the study. These samples were examined macroscopically as well as microscopically. Both swabs and sputum samples were cultured on Sabouraud's Dextrose Agar (SDA) separately and were incubated at $37^{\circ} \mathrm{C}$ and examined after 48 hrs. Growth of cream coloured pasty colonies was suggestive of Candida species and they were further identified by simple staining, germ tube test, sugar fermentation test and Sugar assimilation test, Chlamydospore detection test. The antifungal susceptibility testing was performed according to the Clinical and Laoratory Standards Institute recommended Kirby-Bauer susceptibility testing method. ${ }^{14}$ The data obtained from questionnaire and laboratory findings were interpreted by using statistical package for social science (SPSS version 11.5)

\section{RESULTS}

Out of total 304 samples of each sputum and throat swabs, $16.45 \%$ and $5.3 \%$ samples respectively were growth positive for fungal culture showing comparatively higher growth positivity in sputum samples. Out of 143 elderly population, $47(32.86 \%)$ showed sputum culture positive while in $96(67.0 \%)$ sputum specimen culture was negative. Of 143 total target population of age 50 years and above, $4.6 \%(14 / 143)$ were swab cultures positive for fungi. Statistically the relationship between age category and throat swab/sputum culture was significant $(\mathrm{p}<0.001)$.

Table 1: Fungal growth positivity in sputum specimens of study population

\begin{tabular}{|l|l|r|l|l|}
\hline \multirow{2}{*}{$\begin{array}{c}\text { Growth } \\
\text { pattern }\end{array}$} & \multicolumn{2}{|c|}{ Population under study } & \multirow{2}{*}{ Total } & \multirow{2}{*}{ p-value } \\
\cline { 2 - 3 } & \multicolumn{1}{|c|}{$\begin{array}{c}\text { Above } \\
50 \text { Years }\end{array}$} & & \\
\hline Growth & $3(1.9 \%)$ & $47(32.87 \%)$ & $50(16.45 \%)$ & \\
\hline No growth & $158(98.13 \%)$ & $96(37.13 \%)$ & $254(83.55 \%)$ & $p<0.001$ \\
\hline Total & $161(100.0 \%)$ & $143(100.0 \%)$ & $304(100.0 \%)$ & \\
\hline
\end{tabular}

Table 2: Fungal growth positivity on throat swab culture in the study population

\begin{tabular}{|c|c|c|c|c|}
\hline \multirow{2}{*}{$\begin{array}{c}\text { Growth } \\
\text { Pattern }\end{array}$} & \multicolumn{2}{|c|}{ Population under study } & \multirow{2}{*}{ Total } & \multirow{2}{*}{ p-value } \\
\cline { 2 - 4 } & $=<\mathbf{5 0}$ years & $\begin{array}{c}\text { Above } \mathbf{5 0} \\
\text { years }\end{array}$ & & \\
\hline Growth & $2(1.24 \%)$ & $14(9.8 \%)$ & $16(5.3 \%)$ & \multirow{2}{*}{$<0.001$} \\
\hline No growth & $159(98.75 \%)$ & $129(42.43 \%)$ & $288(94.73 \%)$ & \\
\hline Total & $161(100.0 \%)$ & $143(100.0 \%)$ & $304(100.0 \%)$ & \\
\hline
\end{tabular}

C. albicans was most frequently encountered in sputum samples of study population. In the case of population of age above 50 years (143), highest number i.e. 23 showed presence of $C$. albicans followed by C. tropicals (5), $C$. stelloide (3), C. pseudotropicalis (3), C. guilliermondii (2), C. krusei (1) and C. parapsilosis (1). However only two species of Candida, C. albicans (2) and $C$. krusei (1) were isolated from the sputum specimen of total 161 objects of age less or equal to 50 years (Table 3 ). The distribution of Candida species was significant with age category of the study population $(\mathrm{p}<0.001)$. In the case of throat swab specimen, prevalence of Candida species was higher in elderly population as compared to non elderly population. Only four species of Candida i.e. C. albicans, C. tropicals, C. guilliermondii and $C$. krusei were isolated. Comparatively C. albicans presence was highest (8) (Table 4). The prevalence of Candida species in swab cultures was insignificantly related with the age group of the population $(\mathrm{p}>0.001)$.

Table 3: Distribution of Candida species obtained in sputum samples of study population

\begin{tabular}{|c|c|c|c|c|}
\hline \multirow{2}{*}{$\begin{array}{l}\text { Candida species } \\
\text { isolated }\end{array}$} & \multicolumn{2}{|c|}{ Study population of age } & \multirow[t]{2}{*}{ Total } & \multirow{2}{*}{$\mathrm{p}$-value } \\
\hline & $=<50$ years & Above 50 years & & \\
\hline No growth & $158(98.14 \%)$ & $105(73.43 \%)$ & $263(86.51 \%)$ & \multirow{9}{*}{$p<0.001$} \\
\hline Candida albicans & $2(1.24 \%)$ & $23(16.08 \%)$ & $25(8.22 \%)$ & \\
\hline Candida tropicalis & $0(0.0 \%)$ & $5(3.5 \%)$ & $5(1.64 \%)$ & \\
\hline Candida pseudotropicalis & $0(0.0 \%)$ & $3(2.1 \%)$ & $3(0.98 \%)$ & \\
\hline Candida stelloide & $0(0.0 \%)$ & $3(2.1 \%)$ & $3(0.98 \%)$ & \\
\hline Candida krusei & $1(0.62 \%)$ & $1(0.7 \%)$ & $2(0.65 \%)$ & \\
\hline Candida guillermondii & $0(0.0 \%)$ & $2(1.39 \%)$ & $2(0.65 \%)$ & \\
\hline Candida parapsilosis & $0(0.0 \%)$ & $1(0.7 \%)$ & $1(0.32 \%)$ & \\
\hline Total & $161(100.0 \%)$ & $143(100.0 \%)$ & $304(100.0 \%)$ & \\
\hline
\end{tabular}


Table 4: Distribution of Candida species isolated from throat swab samples of study population

\begin{tabular}{|l|c|c|c|c|}
\hline \multirow{2}{*}{\multicolumn{1}{|c|}{ Candida species }} & \multicolumn{2}{|c|}{ Study population } & \multirow{2}{*}{ Total } & \multirow{2}{*}{ p-value } \\
\cline { 2 - 3 } & $=<50$ years & Above 50 years & & \\
\hline No growth & $159(98.76 \%)$ & $131(91.60 \%)$ & $290(95.39 \%)$ & \\
\hline Candida albicans & $1(0.62 \%)$ & $8(5.6 \%)$ & $9(2.96 \%)$ & \\
\hline Candida tropicalis & $0(0.0 \%)$ & $2(1.39 \%)$ & $2(0.65 \%)$ & \multirow{2}{*}{$(\mathrm{p}>0.001)$} \\
\hline Candida guillermondii & $0(0.0 \%)$ & $2(1.39 \%)$ & $2(0.65 \%)$ & \\
\hline Candida krusei & $1(0.62 \%)$ & $0(0.0 \%)$ & $1(0.32 \%)$ & \\
\hline \multicolumn{1}{|c|}{ Total } & $161(100.0 \%)$ & $143(100.0 \%)$ & $304(100.0 \%)$ & \\
\hline
\end{tabular}

Among three antimycotic drugs used, Candida isolates was highly susceptible to Ketoconazole and resistant to Fluconazole (Table 5). Candida albicans was found resistant towards Fluconazole as compared to other two antimycotic drugs used.

\section{Table 5: Antimycotic susceptibility pattern of Candida isolates}

\begin{tabular}{|c|c|c|c|c|c|c|c|c|}
\hline \multirow{3}{*}{ Candida Isolate } & \multicolumn{8}{|c|}{ Antifungal agent } \\
\hline & \multicolumn{3}{|c|}{ Fluconazole $(25 \mu \mathrm{g} / \mathrm{ml})$} & \multicolumn{3}{|c|}{ Itraconazole (conc) } & \multicolumn{2}{|c|}{ Ketoconazole (conc) } \\
\hline & $\mathrm{s}$ & 1 & $\mathrm{R}$ & $S$ & 1 & $\mathrm{R}$ & $S$ & $R$ \\
\hline Candida albican ( $\mathrm{n}=36$ ) & $\begin{array}{l}1 \\
(2.8 \%)\end{array}$ & \begin{tabular}{|l}
3 \\
$(8.3 \%)$
\end{tabular} & \begin{tabular}{|l|}
32 \\
$(88.9 \%)$
\end{tabular} & \begin{tabular}{|l|}
16 \\
$(44.4 \%)$
\end{tabular} & \begin{tabular}{|l}
4 \\
$(11.1 \%)$
\end{tabular} & $\begin{array}{l}16 \\
(44.4 \%)\end{array}$ & \begin{tabular}{|l|}
24 \\
$(66.6 \%)$
\end{tabular} & $\begin{array}{l}12 \\
(33.3 \%)\end{array}$ \\
\hline $\begin{array}{l}\text { Candida tropicalis } \\
(\mathrm{n}=7)\end{array}$ & $\begin{array}{l}6 \\
(85.7 \%)\end{array}$ & \begin{tabular}{|l|l|}
1 \\
$(12.3 \%)$ \\
\end{tabular} & & $\begin{array}{l}3 \\
(48.9 \%)\end{array}$ & $\begin{array}{l}2 \\
(28.7 \%)\end{array}$ & $\begin{array}{l}1 \\
(12.3 \%)\end{array}$ & $\begin{array}{l}7 \\
(100 \%)\end{array}$ & \\
\hline $\begin{array}{l}\text { Candida guiliermondii } \\
(\mathrm{n}=4)\end{array}$ & $\begin{array}{l}2 \\
(50 \%)\end{array}$ & & $\begin{array}{l}2 \\
(50 \%)\end{array}$ & $\begin{array}{l}3 \\
(75 \%)\end{array}$ & & $\begin{array}{l}1 \\
(25 \%)\end{array}$ & $\begin{array}{l}3 \\
(75 \%)\end{array}$ & $\begin{array}{l}1 \\
(25 \%)\end{array}$ \\
\hline $\begin{array}{l}\text { Candida } \\
\text { pseudotropicalis ( } \mathrm{n}=3 \text { ) }\end{array}$ & $\begin{array}{l}2 \\
(66.6 \%) \\
\end{array}$ & & $\begin{array}{l}1 \\
(33.3 \%) \\
\end{array}$ & $\begin{array}{l}2 \\
(66.6 \%) \\
\end{array}$ & $\begin{array}{l}1 \\
(33.3 \%) \\
\end{array}$ & & $\begin{array}{l}3 \\
(100 \%) \\
\end{array}$ & \\
\hline Candida krusei $(n=3)$ & $\begin{array}{l}1 \\
(3.3 \%)\end{array}$ & \begin{tabular}{|l|}
1 \\
$(33.3 \%)$ \\
\end{tabular} & $\begin{array}{l}1 \\
(33.3 \%)\end{array}$ & $\begin{array}{l}1 \\
(33.3 \%) \\
\end{array}$ & & $\begin{array}{l}2 \\
(66.6 \%) \\
\end{array}$ & $\begin{array}{l}1 \\
(33.3 \%)\end{array}$ & $\begin{array}{l}2 \\
(66.6 \%)\end{array}$ \\
\hline Candida stelloide ( $\mathrm{n}=3$ ) & & & $\begin{array}{l}3 \\
(100 \%)\end{array}$ & $\begin{array}{l}1 \\
(33.3 \%)\end{array}$ & & $\begin{array}{l}2 \\
(66.6 \%)\end{array}$ & $\begin{array}{l}1 \\
(33.3 \%)\end{array}$ & $\begin{array}{l}2 \\
(66.6 \%)\end{array}$ \\
\hline $\begin{array}{l}\text { Candida parapsilosis } \\
\text { (1) }\end{array}$ & & & $\begin{array}{l}1 \\
(100 \%)\end{array}$ & & & $\begin{array}{l}1 \\
(100 \%)\end{array}$ & & $\cdot \mid \begin{array}{l}1 \\
(100 \%)\end{array}$ \\
\hline
\end{tabular}

\section{DISCUSSION}

In this study, out of total 304 samples of each sputum and throat swabs $16.45 \%$ and $5.3 \%$ samples respectively were growth positive for fungal culture showing comparatively higher growth positivity in sputum samples. Sputum and swabs are the best specimens used for isolation of yeast and molds especially in case of fungal respiratory tract infection. However sputum sample is better for higher recovery of fungi. ${ }^{15} \mathrm{In}$ present study in total, Candida species (55), Aspergillus species (8), Penicillum species (1) and Rhizopus species (1) were isolated from both sputum and throat swab samples with Candida species being the most prevalent. However molds like Aspergillus, Penicillium and Rhizopus are also frequently encountered in sputum and throat swab cultures. ${ }^{15,16 .}$

In our study, fungal culture positivity of both sputum and swab were found higher in elderly people (having age above 50 years) than those with age $\leq 50$ years. Fungal prevalence is more in elderly population because their immune defenses have been altered by old age. ${ }^{16}$

In the present study, of the total $133(43.75 \%)$ male respondents, growth was obtained in $12.78 \%(17 / 133)$ sputum samples while among 171 (56.25\%) female respondents, the growth was obtained in $19.30 \%$ (33/171) sputum samples. The growth was more preponderance in the females. This may be due to higher number of female respondents than male respondents enrolled for the study. However distribution of fungal culture positivity with sex was statistically insignificant $(\mathrm{p}>0.001)$.

In the study total number of Candida species isolated was 55 (14 from the swab sample and 41 from the sputum sample). Seven species of Candida were obtained from sputum and throat swab culture. These include C. albicans, $C$. tropicals, C. stelloide, $C$. pseudotropicalis, C. guilliermondii, C. krusei and Candida parapsilosis. Higher number of Candida species were observed in sputum sample than in throat swab. This findings is in accordance to the findings done in Kathmandu where higher number of Candida species were isolated from sputum sample. ${ }^{17}$ The study indicates higher susceptibility of higher age group for Candida or its infection. Similar to our observation, in a study by Jha et al., the commonest species of Candida isolated from sputum was found to be $C$. albicans followed by Candida tropicalis. Non-albicans Candida may be of high clinical significance mainly in case of the patients with predisposing risk factors. ${ }^{17,18}$

In this study different Candida species were tested for azole antifungal drugs. Among three antimycotic drugs used, Ketoconazole was highly susceptible by $68.42 \%$ against the Candida isolates where as fluconazole was more resistance by $70.17 \%$. In present study antimycotic susceptibility test was performed by disc diffusion assay. However estimation of MICs is more definitive in interpreting the results. This study has indicated that ketoconazole is effective antifungal agent for the treatment of infection by Candida species. The yeast and molds positivity in the sputum culture was significantly associated with the presence of health problem in the study population while swab culture positivity had no significant association. Sputum of respondents above 50 years and having health problem showed high positivity towards the Candida species growth as well Aspergillus species growth. This might 
indicates yeasts and molds can be health harshening agents in the people having age above 50 years. The yeast and molds positivity in the sputum culture was significantly associated with the presence of respiratory tract problem in the study population while swab culture positivity had no significant association. Candida and Aspergillus species were more prevalent in the above 50 years people with respiratory tract problem.

\section{CONCLUSION}

The populations with age above 50 years were more susceptible to the Candida infection both in upper and lower respiratory tract. Among the Candida isolates, C. albicans were found predominant. Most of the isolated Candida species were resistant to fluconazole and susceptible to Ketoconazole. Candida and molds positivity in the sputum culture was significantly associated with the presence of respiratory tract problem. Smoking habits and the Carbohydrates diet can be the enhancing factor for the fungal infection in the respiratory tract with the associated symptoms of irritation and discomfort in the throat.

\section{ACKNOWLEDGEMENT}

The authors would like to thank all who contributed directly or indirectly in carrying out of this research.

\section{REFERENCES}

1. William ED, Peter GP, Jack DS. Clinical Mycology. 2nd ed. 198 Madison Avenue, New York : Oxford University Press, Inc; 2003.

2. Tulumoglu S, Kariptas E, Erdem B. Identification and antifungal Susceptibility of Candida isolates from various clinical specimen in doctor Behcet UZ hospital. Anatol J Clin Investig, 2009; 3(3):170-3.

3. Jha BK, Singh YI, Khanal LK, Yadab V, Sanjana RK. Prevalence of asymptomatic bacteriuria among elderly diabetic patients residing in Chitwan. KUMJ, 2009; 7(2):157-61.

4. Ha JF, Italiano CM, Heath $\mathrm{CH}$, Shih S, Rea S, Wood FM. Candidemia and invasive candidiasis: A review of the literature for the burns surgeon. Burns, 2011; 37(2):181-95.

5. Cheesbrough M. District Laboratory Practice in Tropical countries. 2 ed. UK: Cambridge University Press; 2006.

6. Akpan A, Morgan R. Oral candidiasis. Postgrad Med J, 2007; 78:455-159.

7. Meurman JH, Siikala E, Richardson M, Rautemaa R. Non-Candida albicans Candida yeasts of the oral cavity. In: A M-V, editor. Communicating Current Research and Educational Topics and Trends in Applied Microbiology. Manchester: Formatex Publishing; 2007; 719-131.

8. Pfaller M, Diekema D. Epidemiology of invasive candidiasis: a persistent problem. Clin Microbiol Rev, 2007; 20(1):13363

9. Pappas P. Invasive candidiasis. Infect Dis Clin North Am, 2006; 20(3):485-506.

10. Diekema D, Arbefeville S, Boyken L, Kroeger J, Pfaller M. The changing epidemiology of healthcare-associated candidemia over three decades. Diagn Microbiol Infect Dis, 2012; 73(1):45-8.

11. Lewis RE. Overview of the changing epidemiology of candidemia. Curr Med Res Opin, 2009; 25(7):1732-40.

12. Khan S, Singhal S, Mathur T, Upadhyay D, Rattan A. Antifungal susceptibility testing method for resource constrained laboratories. Indian Journal of Medical Microbiology, 2006; 24(3):171-6.

13. Wise MG, Healy M, Reece K, Smith R, Walton D, Dutch W, et al. Species identification and strain differentiation of clinical Candida isolates using the DiversiLab system of automated repetitive sequence-based PCR. J Med Microbiol, 2007; 56(6):778-187.

14. Clinical and Laboratory Standards Institute Method for Antifungal Disk Diffusion Susceptibility Testing of Yeasts; Approved Guideline $2^{\text {nd }}$ Wayne: Clinical and Laboratory Standards Institute; 2009.

15. Andrew M, Micheal D, Laurance D, Jacqueline C, Loicfavennec S. Lack of standardization in the procedures for mycological examination of sputum samples from CF patients:a possible cause for variations in the prevalence of filamentous fungi. Medical Mycology, 2010; 48:88-97.

16. Pfaller M. Nosocomial Fungal Infections, Epidemiology of Candidiasis. Journal of Hospital Infection, 1995; 30:329-38.

17. Sharma M, Pant ND, P andey P. Prevalence of Non-Albicans Candida Among the Patients Attending a Tertiary Care Hospital in Kathmandu, Nepal. Nepal Journal of Biotechnology, 2016; 4(1):43-6.

18. Jha BK, Dey S, Tamang MD, Joshy ME, Shivananda PG, Brahmadatan KN: Characterization of candida species isolated from cases of lower respiratory tract infection. KUMJ. 2006; 4(3):290-294.

19. William J, Ekaterina AE, Mark JM. Association of residential dampness and mold with respiratory tract infections and bronchitis: a meta-analysis. Environmental Health, 2010; 9:72. 